\title{
The Road to Higher Prices: Will Improved Road Standards Lead to Higher Housing Prices?
}

\section{Theis Theisen $^{1}$ (D) Anne Wenche Emblem ${ }^{1}$}

Published online: 14 March 2020

(C) The Author(s) 2020

\begin{abstract}
We study the impact of improved road standards on housing prices in a region of Southern Norway, where towns are located along the coast, like pearls on a string, with sparsely populated areas between the towns. In this region towns have since long been linked together by a road, but in 2009 a new highway, roughly parallel to the old road, was opened. The new highway runs Eastwards from the main town in the region and reduced one-way commutes to the main town by $10-15 \mathrm{~min}$. We examine how this change in transportation infrastructure has affected housing prices, using difference-in-difference regressions to identify the impact of the new highway. Three smaller towns located East of the main town constitute the treatment region, while four towns and communities West of the main town form the control region. We find that the new highway on average increased housing prices in the treatment region by about $5 \%$, but the effect on price differed substantially between the towns. The full impact on housing prices materialized when the new highway was opened. We estimate that the increase in total housing capital in the treatment region amounts to almost $84 \%$ of the construction costs of the new highway.
\end{abstract}

Keywords Road investments · Infrastructure investments · Housing prices · Difference-indifference

\section{Introduction}

Since the contributions of Mohring (1961), Alonso (1964), Muth (1969), Mills (1972), Solow (1972) and others, the relationship between housing (land) prices and monetary

Theis Theisen

Theis.Theisen@uia.no

Anne Wenche Emblem

Anne.Wenche.Emblem@uia.no

1 Department of Economics and Finance, School of Business and Law, University of Agder, P.O. box 422, 4604 Kristiansand, Norway 
and time costs of commuting has been at the core of urban economics. Empirical analysis of the relationship between transportation infrastructure and housing prices appeared much later, and as noted by Mikelbank (2004), the vast majority of such studies have considered rail-based transportation. Among the few studies of non-rail systems are Voith (1993) and Waddell et al. (1993), who examined how road-access to the central business district (CBD) in the metropolitan areas of Philadelphia and Dallas impacted housing prices. They both found that dwellings were sold at higher prices when access to roads leading to the CBD were good. Similar results were obtained by Osland et al. (2007), who studied housing price gradients in a Norwegian region. All these studies of road-access have one important feature in common: they consider comprehensive and already existing road systems, not new roads or single road connections. Hence, these studies do not give an explicit answer to the issue we address in the sequel: how will the opening of a new road of a specific and well-defined type affect housing prices? An answer to this question will be highly relevant to decisions of whether to invest in new roads.

Chernobai et al. (2011) is one of the few examinations of how a new road affects housing prices. Their study is based on data generated through a natural experiment: the opening of a new 14 miles stretch of Interstate 210 between San Bernadino and Los Angeles. The researchers found that the new road had a positive impact on housing prices, particularly for houses located near a ramp giving access to the highway. Prices of houses close to the highway, but not near a ramp were, however, negatively affected due to noise, etc. Kilpatrick et al. (2007) found similar results, but in contrast to Chernobai et al. (2011) the study of Kilpatrick et al. was not based on a natural experiment. Except for Chernobai et al. (2011), the literature on how a new road impacts housing prices is very scant. The goal of the present paper is therefore to contribute to a better understanding of how new roads affect housing prices.

When studying the impact of a new road on housing prices, it is important to take into account the geographical environment into which the new road is introduced. Chernobai et al. (2011) focused mainly on how access to Interstate 210 affects housing prices in the area where a new section of this road was opened, while the role this road plays in the regional transportation system was given less attention. By contrast, Gjestland et al. (2014) studied the case of new bridges and a tunnel replacing ferryboat connections and found that this significantly impacted housing prices. In a similar vein, Jacoby (2000) found that roads in rural areas of a developing country had a significant positive impact on land prices.

In the sequel, we consider a natural experiment where a new highway connecting several towns, located like pearls on a string, was constructed. The new highway runs more or less parallel to the old road. We address how housing prices were affected by the new highway. Drivers may choose between using the new highway or the old road. The new highway is only marginally shorter than the old road, but the time saved by using the new highway is substantial. Users of the new highway must, however, pay a toll, while there is no toll on the old road. To the best of our knowledge, the impact on housing prices of this type of infrastructure project has not previously been studied. Our main research question is therefore: How did the new highway impact housing prices in the region?

The fact that several smaller towns in our case are located at varying distance from a larger town, and that all towns are located along both the new highway and the old road triggers a second research question: Was the impact of the new 
highway on housing prices the same in all the smaller towns, or was the impact different from town to town? To this we add a third research question: Did the new highway affect housing prices also in the larger town? Finally, we address a fourth research question: When in time was the new highway discounted into housing prices? If households are fully rational, one may - from a purely theoretical point of view - argue that the new highway should be discounted into housing prices at the time when the decision to build it was made. Several empirical studies have shown, however, that infrastructure projects usually are not fully discounted into housing prices at the point in time when the decision to carry out the project is made. An examination of this issue is therefore of considerable interest.

Based on the answers to the research questions stated above, it will be possible to examine an additional issue: How much was the aggregate housing capital in our study region affected by the new highway, and how does this compare to the costs of constructing the new highway? As demonstrated by Gjestland et al. (2014), an answer to this question may be useful in a cost benefit analysis of the new highway. We restrict ourselves at this point, however, and do not present a full-blown cost benefit analysis.

In the following, we use data on sales prices of dwellings sold in the period prior to the decision to build the new road was made, during the construction period, as well as in the years after the completion of the new highway. Complementing the data from the region where the new highway was built with data from a control region, we use a difference-in-difference approach. The results from our analysis are striking: First, we find that the new highway is discounted into housing prices in two of the three towns located along the road. The price increase is higher in the town located nearest to the major town, and somewhat less in the most distant of these two small towns. For the third town in our treatment region we find that the new highway had no significant impact on housing prices, possibly because the distance between this town and the major town is on the borderline of what households consider to be an acceptable distance of daily commuting. Next, we find that the new highway was fully discounted into housing prices in the smaller towns when it was opened for traffic. Finally, we find that the increase in total housing capital in the two affected towns amounts to almost $84 \%$ of the construction costs for the new highway.

In the next section we describe in more detail the case addressed. Thereafter, we examine the impact of a new highway on housing prices within a theoretical framework. The econometric model is then set out, followed by a description of the data. Next, empirical results are presented and discussed, supplemented by some robustness checks. The final section concludes.

\section{The Case and the Study Area}

We consider a new highway connecting towns on the South-Eastern coast of Norway, see Fig. 1. The intention to build the new highway was first announced by the Ministry of Transport (2000a, 2000b), but the final decision was not made until February 2005. Construction started in 2007 and was completed in August 2009. The project was carried out as the first large public-private partnership project in Norway, and received considerable attention, not only in the region where the highway was built, but also nationally. 


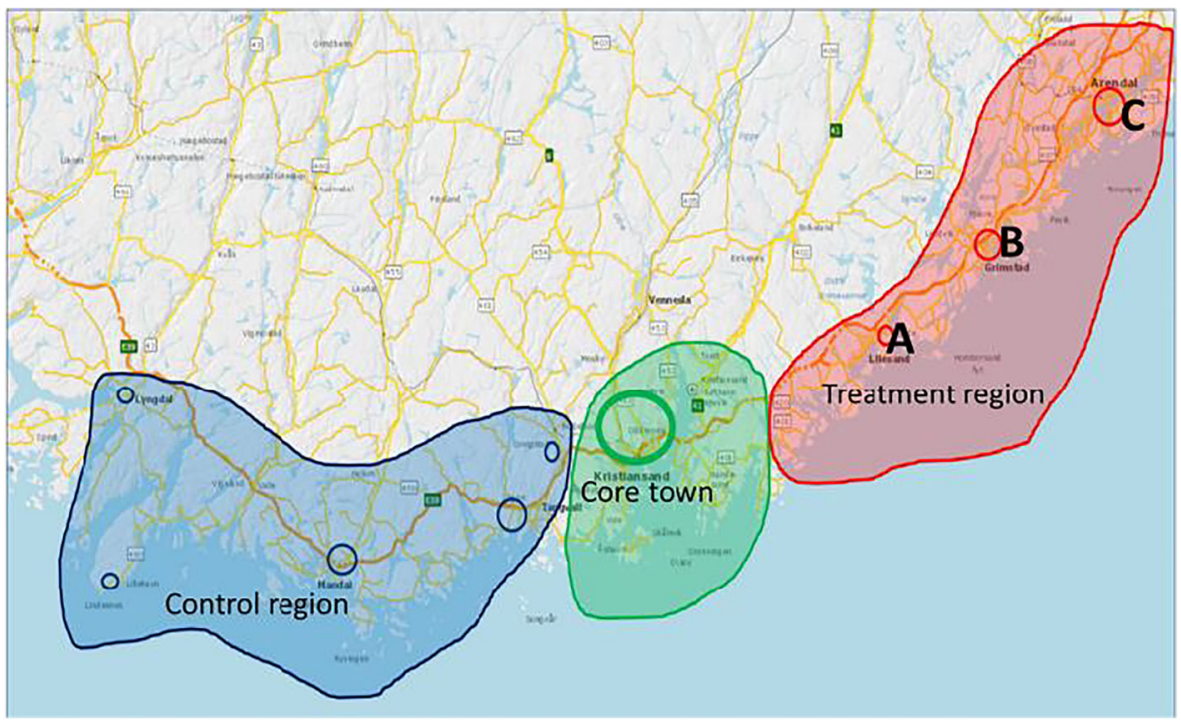

Fig. 1 Geographical location of the regions and towns subject to study

The new highway is only marginally shorter than the old road, but of significantly higher standard. The new highway is a four-lane highway with a maximum speed limit of $100 \mathrm{~km} / \mathrm{h}(62 \mathrm{miles} / \mathrm{h})$, while the old road has two lanes and a speed limit of 60 $80 \mathrm{~km} / \mathrm{h}$ (37-50 miles/h). ${ }^{1}$ Hence, compared to the old road, the new highway has reduced travelling time between the town of Kristiansand (Core in Fig. 1) and Grimstad (B in Fig. 1) from $45 \mathrm{~min}$ to $30 \mathrm{~min}$. Between the two towns just mentioned is the smaller town of Lillesand (A in Fig. 1), from which travelling time to Kristiansand was reduced by $10 \mathrm{~min}$. The new highway is also much safer than the old road and has substantially reduced the risk of traffic delays caused by road-accidents and congestion. Consequently, travelling time along the new highway is not only reduced, but is also much more predictable than along the old road. ${ }^{2}$

Already in year 2000 a high-quality road, which at several points contains two parallel lanes facilitating bypassing, was opened between the town of Arendal ( $\mathrm{C}$ in Fig. 1) and Grimstad. When the new highway between Kristiansand and Grimstad opened, travelling time between the town of Kristiansand and Arendal was reduced from 65 to $50 \mathrm{~min}$. According to the Swedish study of Sandow and Westin (2010), $50 \mathrm{~min}$ is close to the maximum time that people (in Scandinavia) are willing to spend on a one-way daily commute. In order to examine whether the housing market also in Arendal was affected by the new highway Grimstad - Kristiansand, we include the town of Arendal in the treatment region in our empirical examination.

In the following, we undertake a difference-in-difference analysis of a treatment region encompassing three towns: Lillesand (TreatA), Grimstad (TreatB) and Arendal (TreatC). The control region consists of communities located West of Kristiansand,

\footnotetext{
${ }^{1}$ Conversion factor: 1 mile $=1.609344 \mathrm{~km}$.

${ }^{2}$ Along the old road, large vehicles had problems keeping up the speed in a hilly environment. Particularly in winter there were delays and accidents on the old road, which sometimes had to be closed for the time it took to clear the road after accidents.
} 
where there have been no major changes in road conditions in the period considered. The control region includes the two semi-urban municipalities Søgne and Sogndalen located 15-25 km (9-16 miles) West of Kristiansand, the town of Mandal located $40 \mathrm{~km}$ (25 miles) West of Kristiansand, and the village-type community of Lyngdal and the more rural municipality of Lindesnes, both about $70 \mathrm{~km}$ (43 miles) West of Kristiansand. The location of these communities is shown in Fig. 1. The fact that both the treatment and the control region include towns located not farther than $70 \mathrm{~km}$ (43 miles) Eastwards or Westwards of Kristiansand, ensures that the two regions are good matches.

Kristiansand is the fifth largest town in Norway, and the largest town in our sample. Kristiansand municipality has a population of 84,500 , and a total of 29,600 registered workplaces, with $84 \%$ of the employed residents working within the municipality's borders. ${ }^{3}$ In the treatment region, Lillesand has a population of 10,000, Grimstad 21,600 , and in both towns $50 \%$ of the working residents are employed within the municipality. The largest town in the treatment region, Arendal, has a population of 44,500 , and 13,200 registered workplaces, with $75 \%$ of the employees having their workplace within the borders of the municipality. In the control region, Sogndalen/ Søgne has a population of 15,700, Mandal 14,400, and Lindesnes and Lyngdal 11,100. Figure. 2 shows the population growth in the three regions since 1992. During our observation period, 2003-2013, the difference in growth rates between the treatment region and the control region has been small, suggesting that our choice of control region is appropriate.

Our hypothesis is that the new highway has affected real estate markets, mainly through increased integration of labor markets in the towns in the treatment region and the Core town. Official statistics show that commuting between the treatment region and the Core town increased after the new highway was opened. Notice also that the new highway runs through areas where there are almost no houses negatively affected by traffic noise. Along the old road, a few houses have experienced reduced traffic noise after the new highway opened. The number of houses benefiting from lower noise is, however, much too small to be taken explicitly into account in the empirical analysis. Hence, in contrast to the emphasis on externalities in the studies of Kilpatric et al. (2007) and Chernobai et al. (2011), we can disregard this issue.

\section{Theoretical Model}

Let us assume a monocentric town with all workplaces located at a single spot: the central business district (CBD). Households derive utility from a Hicksian composite good $x$, housing, $h$, and leisure, $l$. The utility function takes the form $U(x, h, l)$, with strictly positive marginal utilities $U_{x}, U_{h}$, and $U_{l}$. Consider a household residing at a distance $D$ from the CBD. The household's time budget is given by $T=E+l+t D$, where $T$ is total hours available, $E$ is hours worked, which by assumption is taken to be exogenous, and $t$ is time used per kilometer roundtrip for commuting to work within the town. Let $w$ be the (after-tax) wage rate and $p(D)$ the unit cost of housing. Monetary

\footnotetext{
${ }_{3}^{3}$ The numbers of population and workplaces in this paragraph refer to 2008 , the midpoint of our observation period.
} 


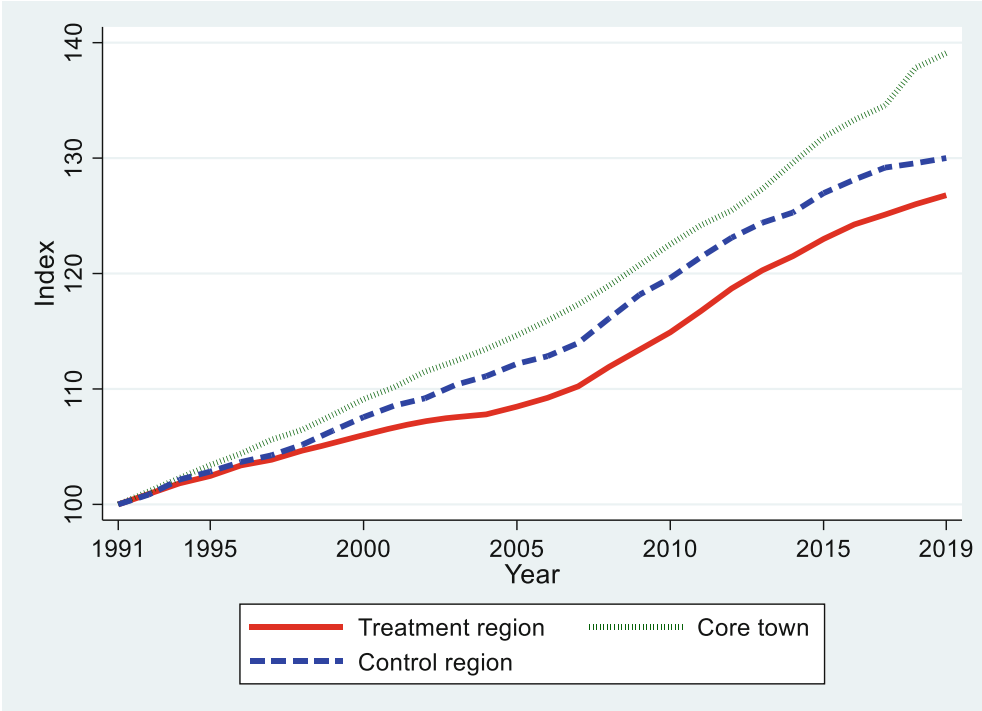

Fig. 2 Population growth in the three regions, based on data from Statistics Norway

costs of transportation amount to $\alpha D$, where $\alpha$ is the costs per kilometer roundtrip. We then obtain the household's monetary budget constraint $w E=x+p(D) h+\alpha D$, where unit cost of the numeraire good $x$ equals 1 . Abstracting from non-commuting travels, and writing $S=T-E$ for the exogenous non-working (spare) time, a household residing at distance D from the CBD maximizes $U(w E-p(D) h-\alpha D, h, S-t D)$ with respect to housing. This yields the first-order condition $U_{h} / U_{X}=p$, which together with the monetary budget yields the Marshallian demands $x=f_{x}(1, p(D), w E-\alpha D, S-t D)$ and $h=f_{h}(1, p(D), w E-\alpha D, S-t D)$. Inserting these into the utility function yields the indirect utility function $V(1, p(D), w E-\alpha D, S-t D)$. If households are identical in all respects, they will - in a spatial equilibrium - obtain the same utility level, $V^{o}$, irrespective of where in the town they reside.

The single-town model is valid for any town considered in isolation. We now extend it to the case of two neighbouring towns, the Core town (CO) and the A-town (A), located at distance $\bar{D}$ from each other, and connected by a road. The two towns have a total population $N$, with $N_{C O}^{0}$ initially residing in the Core town and $N_{A}^{0}$ in the A-town. Hence, $N_{C O}^{0}+N_{A}^{0}=N$, where total population throughout this section is taken to be exogenously given. By assumption, the population of the Core town is substantially larger than that of the A-town, and the utility obtained by households in both towns is identical: $V^{o}$. Hence, initially there is a spatial equilibrium in which households have no incentive to move from one town to the other. To keep the model transparent, we also assume that households initially only commute to work within their town of residence, not between towns. Hence, the initial equilibrium condition is:

$$
\begin{aligned}
& V\left(1, p\left(D_{A}, N_{A}^{0}\right), w_{A}^{0} E-\alpha D_{A}, S-t D_{A}\right) \\
= & V\left(1, p\left(D_{C O}, N_{C O}^{0}\right), w_{C O}^{0} E-\alpha D_{C O}, S-t D_{C O}\right)
\end{aligned}
$$


where we have modified the housing price function so that housing prices not only depend on distance to $\mathrm{CBD}\left(D_{A}\right.$ in town $\mathrm{A}$ and $D_{C O}$ in the Core town), but also on town-size, measured by population. In accordance with standard urban economics theory, we assume that housing prices at a given location within a town are higher the larger the population of the town. Under these assumptions, a spatial equilibrium requires that wages in the two towns, $w_{C O}^{0}$ and $w_{A}^{0}$, differ, and since the Core town is largest, $w_{C O}^{0}>w_{A}^{0}$. The higher wages in the Core town compensate its residents for higher housing prices than in the A-town.

A household in the A-town will choose to commute to work in the Core town if this increases the household's utility. Since such commuting by assumption does not take place in the initial situation, the following inequality, where $t_{A C O}$ is time used per kilometer roundtrip commute between the two towns, must hold in the initial equilibrium, in addition to Eq. (1):

$$
V\left(1, p\left(D_{A}, N_{A}^{0}\right), w_{A} E-\alpha D_{A}, S-t D_{A}\right) \geq V\left(1, p\left(D_{A}, N_{A}^{0}\right), w_{C O} E-\alpha \bar{D}, S-t_{A C O} \bar{D}\right)
$$

Assume now that a new highway is opened between the Core town and the A-town. The new highway implies an improvement in transport infrastructure that reduces travel time between the A-town and the Core town by a factor $0<\gamma<1$. To keep the model tractable, we assume that the new highway neither changes the distance between the two towns nor the monetary costs per kilometer of driving between them, but users of the new highway must pay a toll $b_{A C O}$. A household initially residing in the Core town may consider the option of moving to the A-town, while continuing to work in the Core town. If $\gamma$ and $b_{A C O}$ are sufficiently small, and/or the wage difference $w_{C O}^{0}>w_{A}^{0}$ is sufficiently large, this household may obtain a higher utility by moving to the A-town and commute along the new highway to work in the Core town, than by continuing to reside in the Core town. Hence, some households will move from the Core town to the A-town, thereby reducing the population of the Core town and increasing the population of the A-town. A new spatial equilibrium will then emerge, in which wages in the A-town have increased relative to the initial situation, thereby compensating its residents for higher housing prices induced by the population increase. Conversely, the population decline in the Core town leads to lower wages and lower housing prices there. The condition for the new spatial equilibrium then takes the form:

$$
\begin{gathered}
V\left(1, p\left(D_{A}, N_{A}^{1}\right), w_{A}^{1} E-\alpha D_{A}, S-t D_{A}\right)=V\left(1, p\left(D_{C O}, N_{C O}^{1}\right), w_{C O}^{1} E-\alpha D_{C O}, S-t D_{C O}\right) \\
=V\left(1, p\left(D_{A}, N_{A}^{1}\right), w_{C O}^{1} E-\alpha \bar{D}-b_{A C O}, S-\gamma t_{A C O} \bar{D}\right)
\end{gathered}
$$

This condition tells that in the new spatial equilibrium, households that reside and work in the A-town obtain the same utility as households that reside and work in the Core town, which in turn obtain the same utility as those residing in town A and commuting to work in the Core town. Since $N_{A}^{1}>N_{A}^{0}$ implies $p\left(D_{A}, N_{A}^{1}\right)>p\left(D_{A}, N_{A}^{0}\right)$ and $N_{C O}^{1}$ $<N_{C O}^{0}$ implies $p\left(D_{C O}, N_{C O}^{1}\right)<p\left(D_{C O}, N_{C O}^{0}\right)$, we conclude that a new highway 
reducing travel time between the two towns leads to higher housing prices in the Atown, and lower in the Core town. Moreover, since some households increase their utility by moving from the Core town to the A-town, all households in these towns will in the new spatial equilibrium enjoy a higher utility due to the new highway.

The theoretical model presented above is highly stylized, but may be modified in various ways, for instance by including more than two towns. In order to keep the model tractable, we have abstained from this and other extensions. The model is also in our view so transparent that we have not found it necessary to go through a more formal mathematical derivation of the implications of the model. Notice, however, that the theoretical model describes long-run equilibria. In the short run, limited availability of dwellings in the A-town may imply a larger change in housing prices than in the long run. Finally, we would like to add that gravitation models provide an alternative way to model the consequences of reduced impedance on the intensity of interactions between towns, and on housing prices, see for instance Shen (1999) and Gjestland et al. (2014).

\section{Econometric Model and Estimation Procedure}

We examine the impact of the new highway on housing prices by exploiting house transaction data from the years prior to the decision to build the road was made, as well as from the construction period and the period after it was opened. Following Imbens and Wooldridge (2009) the starting point of our econometric model is a multiple-groups multiple-periods difference-in-difference regression:

$$
\begin{gathered}
\ln P_{i}=\beta^{0}+\sum_{j=1}^{J} \beta^{j} \ln X_{i}^{j}+\sum_{h=1}^{4} \eta^{h} H_{i}^{h}+\theta G_{i}+\sum_{k=1}^{K} \kappa^{k} Z_{i}^{k} \\
+\sum_{t=1}^{T} \tau^{t} Q_{i}^{t}+\sum_{m=1}^{12} \mu^{m} M_{i}^{m}+\bar{Z}_{i} \Omega \bar{Q}_{i}+\varepsilon_{i}^{t}
\end{gathered},(\mathrm{i}=1, . . \mathrm{N}),(t-1, . ., T),
$$

where $P_{i}$ is the price of dwelling $i$. The natural logarithm of the price is assumed to be a function of the natural logarithm of dwelling characteristics, $X_{i}^{j}$, dummy variables denoting type of dwelling, $H_{i}^{h}$, a dummy variable indicating form of ownership, $G_{i}$, dummy variables denoting location, $Z_{i}^{k}$, time-period dummies, $Q_{i}^{t}$, for the year in which the transaction took place, seasonal dummies, $M_{i}^{m}$, for the month of the year in which the transaction took place, a term, $\bar{Z}_{i} \Omega \bar{Q}_{i}$, capturing the impact of the new road and which will be explained more precisely below, and a stochastic error term, $\varepsilon_{i}^{t}$, which is assumed to be normally distributed with zero expectation and a constant variance $\sigma$. Moreover, $\beta^{0}, \beta j, \eta^{h}, \theta, \kappa^{k}, \tau^{t}$ and $\mu^{m}$ are unknown parameters to be estimated.

The term $\bar{Z}_{i} \Omega \bar{Q}_{i}$ on the r.h.s. of Eq. (4) captures treatment effects of the new highway. Here $\bar{Z}_{i}$ is a row vector where each element represents a treatment group (town). If dwelling $i$ is located in a treatment town, the element representing this town equals 1 , while other elements are 0 . Similarly, $\bar{Q}_{i}$ is a column vector with each element representing a treatment period. If dwelling $i$ is sold in a treatment period the element representing this period equals 1 , while other elements are 0 . Finally, $\Omega$ is a parameter matrix where the $r \lambda^{\text {'th }}$ element, $\omega^{r \lambda}$, is the impact parameter for treatment town $r \in R$ in treatment period $\lambda \in \Gamma$, where $R$ is the set 
of treatment towns and $\Gamma$ is the set of treatment periods. If dwelling $i$ is located in treatment town $r$ and sold in year $\lambda$, we obtain: $\bar{Z}_{i} \Omega \bar{Q}_{i}=1 \omega^{r \lambda} 1=\omega^{r \lambda}$ Treat $_{i}^{r \lambda}$, where Treat ${ }_{i}^{r \lambda}$ is a dummy variable equal to 1 for dwelling $i$, and 0 for all other dwellings. The model implies that the time path of housing prices in treatment town $r$ and treatment period $\lambda$ is shifted by $\omega^{r \lambda}$, compared to the underlying common price trend for the treatment region and the control region. From the theoretical model we expect that the new highway manifests itself in an upward shift in housing prices in the treatment towns, implying $\omega^{r \lambda}>0$, but the magnitude of this upward shift may differ between treatment periods and treatment towns.

In our case, we have three treatment towns, and it might be argued that (at least) each year from the year when it was decided to build the road up to one year after construction was completed should be considered as separate treatment periods. This would imply six treatment periods, and $18(3 \times 6) \Omega$-matrix coefficients to estimate. Realizing that the estimation of so many treatment parameters may be too demanding given the available data, we consider simplifications of the model.

First, we simplify by assuming that there is no treatment effect prior to 2007 , i.e. the year when construction of the new road started. Second, we assume that the full treatment effect is reached in 2010, i.e. in the year after the opening of the new highway. Next, when estimating Eq. (4) we exclude observations from the treatment region for the years 2007, 2008, and 2009. With these two restrictions and the exclusion of parts of the data set, we will be left with three treatment parameters to estimate: $\omega^{A 10}$, $\omega^{B 10}$, and $\omega^{C 10}$, with the affiliated treatment variables TreatA10, TreatB10, and TreatC10, where capital letters A, B, C indicate towns in the treatment region, and the number refers to the treatment period. This model is estimated in the empirical section and will be referred to as Regression B. Prior to estimating Regression B we will, however, estimate an even more restricted model, in which we do not distinguish between the three treatment towns. In this model, referred to as Regression A, the treatment variable is defined as Treat $E 10=$ Treat $A 10+$ Treat $B 10+\operatorname{Treat} C 10$. The estimated treatment parameter in Regression A will be a weighted average of the underlying treatment parameters of the three towns, with the number of treated dwellings in each town relative to the total number of treated dwellings as weights. Lastly, we also estimate a third simplified model, referred to as Regression D, which includes separate treatment variables for each of the years 2007, 2008, and 2009, in addition to the treatment variable for the period 2010-2013. In Regression D all treatment towns are lumped together in one treatment group, just as in Regression A.

Unlike Gjestland et al. (2014) and other papers using gravitation models, Eq. (4) does not contain any measures of physical distance or time distance between dwellings and important amenities. The reason for this is twofold: First, although the Core town is the largest town in the region considered, commuting especially from town $\mathrm{C}$ to the Core town is modest. In addition, the balance between jobs and residents in town $\mathrm{C}$ is not that different from in the Core town. Hence, one may argue that there is not one totally dominating center in the region. Moreover, each town represents a sub-center within the treatment region. Consequently, if distance variables had been included, there should be a whole set of such variables. This would, however, easily lead to problems with collinear regressors. Second, while it would have been possible to include variables measuring distance or travel time from dwellings to the nearest ramp to the new highway, such variables would - with our relatively dense set of zip-codes - 
be heavily correlated with the zip-code dummies. Since zip-codes capture also many other differences between locations than average distance from dwellings in the zipcode to the nearest ramp, we will argue that it is more important to keep zip-codes in the model than including distance to the nearest ramp.

The specification of our model follows the recommendations of Cropper et al. (1988) to use either a double-logarithmic form or a Box-Cox transformation when estimating hedonic housing price functions. If important variables are unobserved, or observed with substantial error, they warn against using more complicated specifications. In our case we have only had access to a limited set of independent variables, implying that we cannot disregard that there may be some unobserved variables. Hence, we have chosen the relatively simple double-logarithmic form, but see also the remark on alternative functional forms in footnote 6 below.

In estimating Eq. (4) we account for the fact that data contains co-operative housing units carrying a mutual debt which is paid down through monthly instalments after the transaction has taken place. Since mutual debt is in effect a deferred payment, we define the total price of a co-operative dwelling as $P_{i}=p_{i}+\zeta M U T_{i}$, where $p_{i}$ is the equity (out-of-pocket) price paid at the time of transaction, while $M U T_{i}$ is the mutual debt resting on the dwelling when the transaction takes place, and $\zeta$ is an unknown parameter to be estimated. ${ }^{4}$

The estimation procedure used in the empirical section may be described as follows: We first use a subset of data on non-detached dwellings in the Core town to estimate Eq. (4) by OLS, and using a grid-search procedure to determine the magnitude of $\zeta$ that maximizes Rsquared. ${ }^{5}$ This gives an estimate, $\widehat{\zeta}$, of the mutual debt parameter, which is used in all subsequent estimations. We then estimate different variants of Eq. (4) by OLS, using $\widehat{\zeta}$ as prior information, but the robustness of this procedure will be examined.

\section{Data}

We exploit transaction data for dwellings in nine Norwegian municipalities over the eleven- year period 2003-2013. Three municipalities are included in the treatment region, five in the control region and one constitutes the Core town, cf. Fig. 1. Transaction data were extracted from the database of Eiendomsverdi AS. After excluding observations for which the sales price was not recorded, and observations with item-non-response for floor-space, age of dwelling and location (zip-code), we were left with a sample of 37,216 observations.

Table 1 contains definitions of all basic variables used in the analysis. Descriptive statistics are provided in Tables 2 and 3. The span in sales prices, floor-space, age and lot-size is substantial. Approximately $16 \%$ of the observations are co-operative dwellings, most of which carry a share of the mutual debt of the co-operative to which they belong. Using the procedure described at the end of the last section for estimating the

\footnotetext{
${ }^{4}$ Robertsen and Theisen (2011) demonstrated that in Norway, where interest rates on mutual debt normally fall short of interest rates on private loans, $\zeta<1$, and they obtained the point estimate $\zeta=0.89$.

${ }^{5}$ Since no detached dwellings are co-ops, we delimited the sample that is used for estimating the mutual debt parameter to non-detached dwellings. Under the assumption that housing prices in the Core town are unaffected by the new highway, the restrictions on the treatment parameters are innocuous. The validity of this assumption will, however, be tested later.
} 
Table 1 Variable definitions

\begin{tabular}{|c|c|}
\hline Variable & Definition \\
\hline \multicolumn{2}{|c|}{ Dependent variables: } \\
\hline Price & Sales price, measured in Norwegian kroner (NOK). \\
\hline Mutual & Mutual debt carried by the dwelling considered, measured in NOK. \\
\hline \multicolumn{2}{|c|}{ Dwelling characteristics and lot: } \\
\hline Floor & Floor-space, measured in square meters. \\
\hline Age & Age of dwelling, measured in years. \\
\hline Lot & Lot size exceeding 1000 square meters, measured in square meters. \\
\hline \multicolumn{2}{|c|}{ Dwelling types and ownership: } \\
\hline Co-op & Dummy variable equal to 1 if a co-operative dwelling, 0 otherwise. \\
\hline Detached & Dummy variable equal to 1 if a detached dwelling, 0 otherwise. \\
\hline Twin-house & Dummy variable equal to 1 if a twin-house, 0 otherwise. \\
\hline Row-house & Dummy variable equal to 1 if a row-house, 0 otherwise. \\
\hline Apartment & Dummy variable equal to 1 if an apartment, 0 otherwise. \\
\hline \multicolumn{2}{|c|}{ Treatment variables: } \\
\hline TreatE & Dummy variable equal to 1 if in the treatment region, 0 otherwise. \\
\hline TreatA & Dummy variable equal to 1 if treatment town A (Lillesand), 0 otherwise. \\
\hline TreatB & Dummy variable equal to 1 if treatment town B (Grimstad), 0 otherwise. \\
\hline TreatC & Dummy variable equal to 1 if treatment town $\mathrm{C}$ (Arendal), 0 otherwise. \\
\hline TreatK & Dummy variable equal to 1 if Core town $\mathrm{K}$ (Kristiansand), 0 otherwise. \\
\hline \multicolumn{2}{|c|}{ Location and time dummies: } \\
\hline Zip-codes & $Z_{i}$ equal to 1 for zip-code $\mathrm{i}$, otherwise $0(\mathrm{i}=1, . ., 75)$ \\
\hline Year & Dummy variables equal to 1 if sold in year $t(t=2003-2013), 0$ otherwise. \\
\hline Month & Dummy variables equal to 1 if sold in month $\mathrm{m}(\mathrm{m}=1, . ., 12), 0$ otherwise. \\
\hline
\end{tabular}

mutual debt parameter, we obtained $\widehat{\zeta}=0.86$, which is used as prior information in all subsequent estimations.

The sub-sample sizes shown in the last line of Table 3 implies that almost $30 \%$ of the observations are in the treatment region, a little more than $16 \%$ in the control region, and about $54 \%$ in the Core town. About $39 \%$ of the observations are detached houses, but as seen from Table 3 the share of detached houses is much lower in the Core town (Kristiansand) and substantially higher in the towns and communities included in the treatment and control regions. Moreover, while $41 \%$ of the units in our sample are apartments, Table 3 shows that this share is higher in the Core town and much lower in the rest of the sample. A t-test of whether the share of apartments in the treatment and control regions are equal is not rejected ( $p$ value 0.6024$)$, implying that the structure of the housing market in these two subsamples is similar. Another important observation from Table 3 is that mean sales prices are very similar in the treatment region and the control region, and a t-test of the null hypothesis that mean prices in these two regions are equal is not rejected ( $\mathrm{p}$ value 0.2107 ). An additional observation is that the means of all other variables listed in Table 3 are statistically significantly different between the three subsamples. Hence, it may be important to include these variables as independent variables in our hedonic regressions. Finally, notice from Table 4 that the partial 
Table 2 Descriptive statistics, entire sample, $N=37,216$

\begin{tabular}{|c|c|c|c|c|}
\hline & Mean & Std. Dev. & Min & Max \\
\hline \multicolumn{5}{|c|}{ Dependent variables: } \\
\hline Price & $1,966,910$ & $1,053,614$ & 40,000 & $23,000,000$ \\
\hline Mutual & $46,671.8$ & $187,298.3$ & 0 & $3,440,000$ \\
\hline \multicolumn{5}{|c|}{ Dwelling characteristics and lot: } \\
\hline Floor & 111.3869 & 52.51462 & 16 & 467 \\
\hline Age & 36.89255 & 35.75254 & 0 & 461 \\
\hline $\operatorname{Lot}^{a}$ & 402.2755 & 5104.214 & 0 & 381,354 \\
\hline \multicolumn{5}{|c|}{ Dwelling types and ownership } \\
\hline Co-op & .1649559 & .3711458 & 0 & 1 \\
\hline Detached & .3908534 & .4879482 & 0 & 1 \\
\hline Twin-house & .1018379 & .3024391 & 0 & 1 \\
\hline Row-house & .0940993 & .2919708 & 0 & 1 \\
\hline Apartment & .4132094 & .4924164 & 0 & 1 \\
\hline \multicolumn{5}{|c|}{ Treatment variables } \\
\hline TreatA & .036624 & .1878395 & 0 & 1 \\
\hline TreatB & .082572 & .2752379 & 0 & 1 \\
\hline TreatC & .1793046 & .3836123 & 0 & 1 \\
\hline TreatE & .2985006 & .4576064 & 0 & 1 \\
\hline TreatK & .5382094 & .4985446 & 0 & 1 \\
\hline
\end{tabular}

a. Lot size above 1000 sqm. For non-cooperative dwellings exclusive of apartments

Table 3 Descriptive statistics for subsamples

\begin{tabular}{|c|c|c|c|c|c|c|}
\hline \multirow[b]{2}{*}{ Variable } & \multicolumn{3}{|c|}{ Mean values } & \multicolumn{3}{|c|}{$P$-values for test of different means ${ }^{\mathrm{c}}$} \\
\hline & $\begin{array}{l}\text { Treatment } \\
\text { region }\end{array}$ & $\begin{array}{l}\text { Control } \\
\text { region }\end{array}$ & $\begin{array}{l}\text { Core } \\
\text { town }\end{array}$ & $\begin{array}{l}\text { Treatment } \\
\text { Control }\end{array}$ & $\begin{array}{l}\text { Treatment } \\
\text { Core }\end{array}$ & $\begin{array}{l}\text { Control } \\
\text { Core }\end{array}$ \\
\hline Price & $1,828,969$ & $1,810,550$ & $2,090,853$ & 0.2107 & $0.0000 * * *$ & $0.0000 * * *$ \\
\hline Mutual $^{\mathrm{a}}$ & $402,929.9$ & $921,140.5$ & $238,264.2$ & $0.0000^{* * *}$ & $0.0000^{* * *}$ & $0.0000 * * *$ \\
\hline Floor & 119.9799 & 122.7199 & 103.1826 & $0.0008^{* * *}$ & $0.0000^{* * *}$ & $0.0000 * * *$ \\
\hline Age & 40.51661 & 29.7321 & 37.05502 & $0.0008^{* * * *}$ & $0.0000^{* * *}$ & $0.0000 * * *$ \\
\hline $\operatorname{Lot}^{\mathrm{b}}$ & 693.9936 & 466.2936 & 198.3691 & $0.0339^{*}$ & $0.0061 * *$ & $0.0022 * *$ \\
\hline Co-op & .084436 & .026987 & .2514728 & $0.0000^{* * *}$ & $0.0000^{* * *}$ & $0.0000 * * *$ \\
\hline Detached & .5859213 & .4999177 & .2495756 & $0.0000^{* * *}$ & $0.0000 * * *$ & $0.0000 * * *$ \\
\hline Twin-house & .0864164 & .1316439 & .101348 & $0.0000^{* * *} *$ & $0.0000^{* * * *}$ & $0.0000 * * *$ \\
\hline Row-house & .0559006 & .0929735 & .1156266 & $0.0000 * * *$ & $0.0000^{* * *}$ & $0.0000 * * *$ \\
\hline Apartment & .2717616 & .2754649 & .5334498 & 0.6024 & $0.0000^{* * * *}$ & $0.0000 * * *$ \\
\hline $\mathrm{N}$ & 11,109 & 6077 & 20,030 & & & \\
\hline
\end{tabular}

a. means of mutual debt for dwellings that carry a positive mutual debt

b. Lot size above $1000 \mathrm{sqm}$. For non-cooperative dwellings exclusive of apartments

c. Stars indicate statistical significance, with $p$-values: $* p<0.05, * * p<0.01, * * * p<0.001$ 


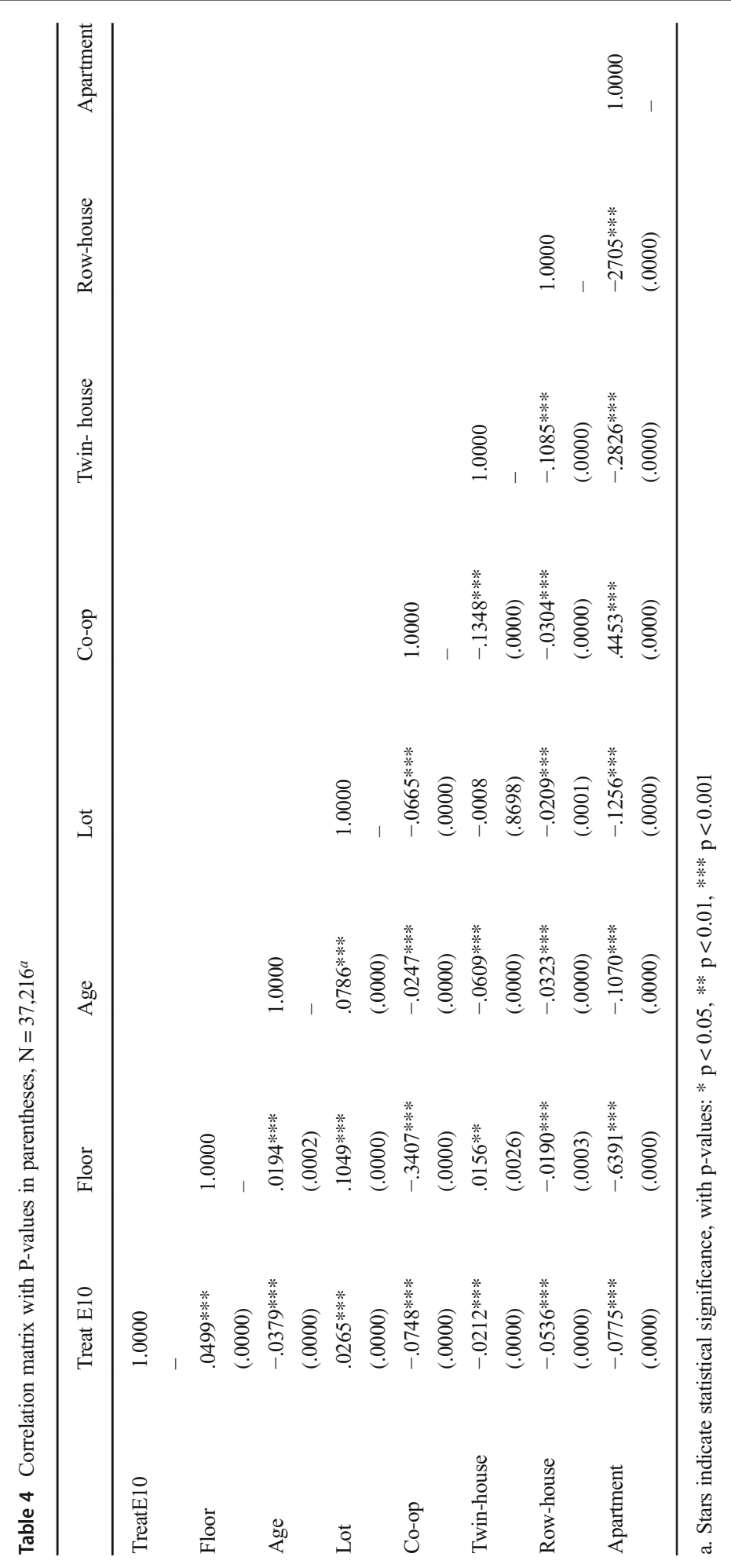


correlation between most independent variables is low. The only exception is the correlation between the apartment dummy and floor-space, but even this is not alarmingly high.

Figure 3 shows box plots of housing price per square meter floor-space for detached dwellings, which dominates the housing market in both the treatment and control regions, and of which there are many also in the Core town. The figure reveals that the median price as well as the change in prices over the entire study period is similar for the treatment region and the control region. The Core town differs, however, in that the price level is higher, and the price increase over the entire period is stronger than in the treatment and control region. The higher price level in the Core town may inter alia be related to the fact that its population is larger than in the other towns and communities. Stronger price growth in the Core town may be related to stronger population growth in the Core town than in the treatment and control regions, cf. Fig. 2. The higher housing price level and growth in the Core town are among the reasons why we have chosen to exclude this town from both the treatment and the control region.

\section{Empirical Results}

Results from estimating various versions of Eq. (4) are shown in Table 5. In Regression A all towns in the treatment region are subsumed under one category, TreatE. The treatment period includes the years 2010-2013, the years 2003-2006 constitute the non-treatment period, while data from the years 2007-2009 are excluded from the estimation. Regression A explains $71 \%$ of the variation in housing prices. The Vif statistics indicate that collinearity of regressors is not a problem, but since the BreuschPagan statistics reveals that error terms are heteroscedastic we use throughout robust standard errors estimated with Huber-White's "sandwich" estimator.

The treatment effect in Regression A is affiliated with the variable TreatE10, where E indicates that the treatment region lies East of the Core town and 10 indicates that the first year in the treatment period, i.e. the first year when the full treatment effect kicks in, is 2010. The impact parameter of TreatE10 in Table 5 is statistically significant and amounts to 0.0488 . Hence, we ascribe an increase in housing prices in the treatment region of almost $5 \%$ to the new highway. ${ }^{6}$ Except for the Apartment dummy, all other independent variables in Regression A that are explicitly shown in Table 5 have a statistically significant impact on housing prices, with signs and magnitudes that are reasonable and in good accordance with previous research. In estimating Regression A we have controlled for the location of dwellings by including zip-codes. Many of these have a strong and statistically significant impact on housing prices, but since they are not of primary interest for the issues we address, they are not shown in Table 5. Dummy

\footnotetext{
${ }^{6}$ We estimated also a variant of Regression $\mathrm{A}$ in which all terms entered linearly, as well as a semilogarithmic function where the dependent variable was log-transformed while all independent variables entered untransformed. In contrast to the double-logarithmic form, the residuals in the two other functional forms deviated substantially from the normal distribution, and heteroskedasticity was also much more pronounced than in the double-logarithmic form we have used throughout the paper. Hence, we do not pay more attention to the linear and semilogarithmic functional forms, but to mention that in the semilogarithmic function the treatment variable, TreatE10, indicated an increase in housing price by $5.4 \%$, while the linear function implied that treatment increased housing prices by $8.4 \%$.
} 


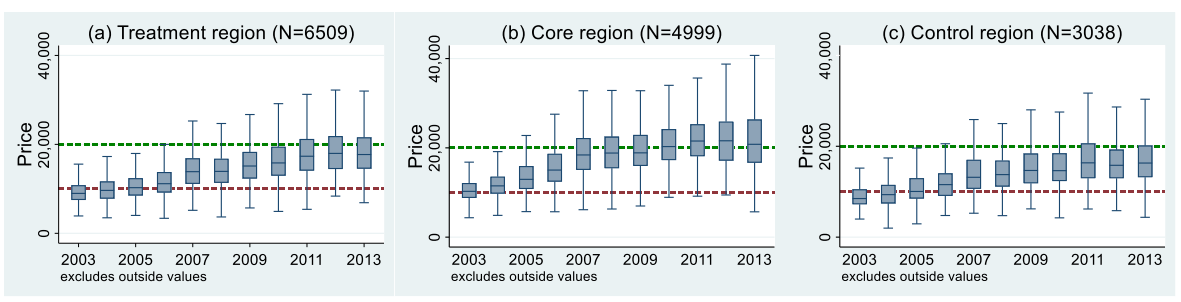

Fig. 3 Boxplot of price per square meter floorspace for detached dwellings

variables for year of transaction, also not displayed in Table 5, have a substantial impact, and similarly to Fig. 3, the coefficients affiliated with the year-dummies reveal that housing prices in the treatment and control region in 2013 were about $70 \%$ higher than in 2003. Finally, the impact parameters of the variables for month of transaction reveal a distinct, but not very strong, seasonal price pattern. However, since this is not at focus in our study, these results are not displayed in Table 5.

In Regression B we have defined separate treatment effects for each town in the treatment region, while maintaining the assumption of only one treatment period. The sample used in estimating Regression B is also identical to that used for Regression A. The estimated treatment parameters in Regression B indicate that the new highway increased housing prices by about $13 \%$ in Lillesand (TreatA10) and by about $9 \%$ in Grimstad (TreatB10). For the third town, Arendal, however, the variable TreatC10 does not carry a statistically significant parameter. Hence, it seems that the new highway has affected housing prices only in towns A and B. As already explained, these towns are directly connected to the new highway. Notice that housing prices increased most in town A, even if the reduction in travelling time to the Core town was only $10 \mathrm{~min}$, compared to $15 \mathrm{~min}$ from town B. Hence, not only the time saved by using the new highway, but also the total time used, or possibly the distance between towns, may matter for how housing prices are affected.

In our empirical analysis we have so far not examined whether housing prices in the Core town were affected by the new highway. From the theoretical model we expect, however, that housing prices in the Core town decline due to the new highway. Regression $\mathrm{C}$, where the Core town now is treated as if it were a treatment town, throws light over this. Regression $\mathrm{C}$ is estimated from a sample including both the Core town and the control region, and with data from the years 2007-2009 still excluded from the sample. We now have only one treatment period and one treatment town, and hence only one treatment parameter to estimate. The positive and statistically significant parameter of variable TreatK10 implies that housing prices increased in the Core town - relative to the control region - after the new highway was opened. The estimated increase in housing prices in the Core town is, however, much smaller than found for towns A and B in Regression B. Hence, the empirical results support the predictions of our theoretical model that housing prices in treatment towns A and B due to the new highway increased relative to the Core town. It should be mentioned, though, that the positive parameter affiliated with TreatK10 may be related to other factors than the new highway. An alternative explanation, inspired by Fig. 2, may be that population growth is higher in the Core town than in the two other regions, especially in the years after the new highway had been completed. If the new highway had not been constructed, one may argue that housing prices in the Core town possibly might have increased even more than our results indicate. It is not possible, however, to be conclusive at this point. 
Table 5 Main results, OLS regressions ${ }^{a}$

\begin{tabular}{|c|c|c|c|c|}
\hline & Regression A & Regression B & Regression C & Regression D \\
\hline TreatE10 & $\begin{array}{l}.0488^{* * *} \\
(.0092)\end{array}$ & & & $\begin{array}{l}.0502 * * * \\
(.0092)\end{array}$ \\
\hline TreatE09 & & & & $\begin{array}{l}.0195 \\
(.0138)\end{array}$ \\
\hline TreatE08 & & & & $\begin{array}{l}-.0255 \\
(.0142)\end{array}$ \\
\hline TreatE07 & & & & $\begin{array}{l}-.0249 \\
(.0145)\end{array}$ \\
\hline TreatA10 & & $\begin{array}{l}.1324 * * * \\
(.0170)\end{array}$ & & \\
\hline TreatB10 & & $\begin{array}{l}.0927 * * * \\
(.0125)\end{array}$ & & \\
\hline TreatC10 & & $\begin{array}{l}.0105 \\
(.0105)\end{array}$ & & \\
\hline TreatK10 & & & $\begin{array}{l}.0344 * * * \\
(.0080)\end{array}$ & \\
\hline Ln (Floor) & $\begin{array}{l}.5825 * * * \\
(.0086)\end{array}$ & $\begin{array}{l}.5828 * * * \\
(.0086)\end{array}$ & $\begin{array}{l}.6338 * * * \\
(.0055)\end{array}$ & $\begin{array}{l}.5850 * * * \\
(.0072)\end{array}$ \\
\hline Ln (Age) & $\begin{array}{l}-.0679 * * * \\
(.0023)\end{array}$ & $\begin{array}{l}-.0676^{* * * *} \\
(.0023)\end{array}$ & $\begin{array}{l}-.0728 * * * \\
(.0018)\end{array}$ & $\begin{array}{l}-.0628 * * * \\
(.0020)\end{array}$ \\
\hline Ln (Lot) & $\begin{array}{l}.0097 * * * \\
(.0013)\end{array}$ & $\begin{array}{l}.0098 * * * \\
(.0013)\end{array}$ & $\begin{array}{l}.0076^{* * * *} \\
(.0013)\end{array}$ & $\begin{array}{l}.0094 * * * \\
(.0011)\end{array}$ \\
\hline Co-op & $\begin{array}{l}-.0382 * * * \\
(.0107)\end{array}$ & $\begin{array}{l}-.0389 * * * \\
(.0107)\end{array}$ & $\begin{array}{l}-.0549 * * * \\
(.0040)\end{array}$ & $\begin{array}{l}-.0421 * * * \\
(.0093)\end{array}$ \\
\hline Twin-house & $\begin{array}{l}-.0740 * * * \\
(.0069)\end{array}$ & $\begin{array}{l}-.0737 * * * \\
(.0069)\end{array}$ & $\begin{array}{l}-.0866^{* * *} \\
(.0053)\end{array}$ & $\begin{array}{l}-.0694 * * * \\
(.0058)\end{array}$ \\
\hline Row-house & $\begin{array}{l}-.1168 * * * \\
(.0074)\end{array}$ & $\begin{array}{l}-.1160 * * * \\
(.0074\end{array}$ & $\begin{array}{l}-.1104 * * * \\
(.0053)\end{array}$ & $\begin{array}{l}-.1127 * * * \\
(.0064)\end{array}$ \\
\hline Apartment & $\begin{array}{l}.0017 \\
(.0086)\end{array}$ & $\begin{array}{l}.0029) \\
(.0086)\end{array}$ & $\begin{array}{l}-.0486 * * * \\
(.0062)\end{array}$ & $\begin{array}{l}.0030 \\
(.0073)\end{array}$ \\
\hline Constant & $\begin{array}{l}11.54 * * * \\
(.0473)\end{array}$ & $\begin{array}{l}11.52 * * * \\
(.0474)\end{array}$ & $\begin{array}{l}11.68 * * * \\
(.0285)\end{array}$ & $\begin{array}{l}11.52 * * * \\
(.0396)\end{array}$ \\
\hline Zip-codes & Yes & Yes & Yes & Yes \\
\hline Years & Yes & Yes & Yes & Yes \\
\hline Months & Yes & Yes & Yes & Yes \\
\hline $\mathrm{R}-\mathrm{Sq}$ & .7100 & .7117 & .8146 & .6911 \\
\hline R-Sq adjusted & .7083 & .7100 & .8139 & .6897 \\
\hline Vif average & 1.93 & 2.05 & 2.11 & 2.10 \\
\hline Vif $\max$ & 4.17 & 4.71 & 5.58 & 4.76 \\
\hline Breusch-Pagan & 55.10 & 58.40 & 301.71 & 69.71 \\
\hline $\mathrm{N}$ & 12,630 & 12,630 & 18,918 & 17,186 \\
\hline
\end{tabular}

a. Dependent variable: Ln (Price+0.86*MUT). Robust (Huber-White) standard errors in parentheses. Stars indicate statistical significance, with * denoting 5\% level, ** $1 \%$ level and *** $0.1 \%$ level 
When estimating Regressions A, B and C, data from the years 2007-2009 were excluded. The rationale behind this is that the treatment effect may have kicked in at any time within the construction period, and possibly gradually. To obtain a correct estimate of the treatment effect we therefore excluded data from the years during which the new highway was under construction. Regression D in Table 5 shows, however, the results from re-estimating Regression A using data for all years 2003-2013, and with separate treatment variables for all four periods 2007, 2008, 2009, and 2010-2013. The magnitude of the estimated treatment parameter affiliated with TreatE10 in Regression $\mathrm{D}$ is statistically significant and with a magnitude that differs only slightly from the estimate of the same parameter in Regression A. In Regression D, however, the coefficient of TreatE07 is supposed to capture the part of the treatment effect occurring already in 2007, i.e. the year when construction of the new highway started. Similarly, TreatE08 and TreatE09 capture the additional treatment effects occurring in 2008 and 2009. The full treatment effect can therefore in principle be found by adding the estimated coefficients of TreatE07, TreatE08, TreatE09 and TreatE10. Since the estimated treatment coefficients for the years before 2010 are not statistically significantly different from zero, however, we have not carried out the addition. To include as much as four treatment periods seems to demand too much from the available data. The fact that only the coefficient of TreatE10 is statistically significant suggests, though, that our presumption that the treatment effect kicks in towards the end of the construction period, or shortly after, seems warranted.

Despite strong indications that the treatment effect kicks in at the very end of the construction period, we supplement the analysis of this issue by re-estimating Eq. (4) under alternative assumptions on when the treatment effect kicks in. We do so by using the full sample from both the treatment region and the control region, and by assuming that the treatment effect fully materializes in 2005 , or alternatively in 2006 , and so on up to 2010. The results of this exercise, which are shown in Table 6, are striking: the magnitude of the estimated treatment coefficient increases from virtually zero in 2005 to almost 0.055 in 2010 . Notice also that the precision with which this coefficient is estimated, as measured by the standard deviation, increases up to 2009. Moreover, the estimated equation explains slightly more of the variation in housing prices if the estimation is carried out under the assumption that the treatment effect fully materializes in either 2009 or 2010 . These observations suggest, like the results for Regression $\mathrm{D}$ in Table 5, that the treatment effect fully materialized when the new highway was opened. Our results on the timing of the treatment effect are also very much in line with Chernobai et al. (2011) who found that most of the effects on housing prices came towards the end of the construction period and in the first years after a new segment of Interstate 210 between San Bernardino and Los Angeles had been opened.

\section{Robustness Considerations}

Tables 7 and 8 show the results from several robustness checks. To facilitate comparison with results in the previous section, the left column in Table 7 replicates the results for Regression A. Next, Rob-1 shows results from estimating Regression A using $\widehat{\zeta}$ $=1.00$ instead of $\widehat{\zeta}=0.86$ which was used as prior information when estimating 
Table 6 Alternative starts of treatment period, OLS regressions, $N=17,186^{a}$

\begin{tabular}{|c|c|c|c|c|c|c|}
\hline & \multicolumn{6}{|c|}{ Year treatment period is assumed to start } \\
\hline & 2005 & 2006 & 2007 & 2008 & 2009 & 2010 \\
\hline \multirow[t]{2}{*}{ Treatment coefficient } & .0032 & .0140 & $.0262 * *$ & $.0398 * * *$ & $.0539 * * *$ & $.0549 * * *$ \\
\hline & $(.0110)$ & $(.0096)$ & $(.0084)$ & $(.0079)$ & $(.0076)$ & $(.0076)$ \\
\hline \multirow[t]{2}{*}{ Ln (Floor) } & $.5845^{* * *}$ & $.5848 * * *$ & $.5850 * * *$ & $.5853^{* * *}$ & $.5853^{* * *}$ & $.5852 * * *$ \\
\hline & $(.0072)$ & $(.0072)$ & $(.0072)$ & $(.0072)$ & $(.0072)$ & $(.0072)$ \\
\hline \multirow[t]{2}{*}{ Ln (Age) } & $-.0629 * * *$ & $-.0629 * * *$ & $-.0629 * * *$ & $-.0628 * * *$ & $-.0628 * * *$ & $-.0627 * * *$ \\
\hline & $(.0020)$ & $(.0020)$ & $(.0020)$ & $(.0020)$ & $(.0020)$ & $(.0020)$ \\
\hline \multirow[t]{2}{*}{$\operatorname{Ln}($ Lot) } & $.0094 * * *$ & $.0094 * * *$ & $.0094 * * *$ & $.0094 * * *$ & $.0094 * * *$ & $.0094 * * *$ \\
\hline & $(.0011)$ & $(.0011)$ & $(.0011)$ & $(.0011)$ & $(.0011)$ & $(.0011)$ \\
\hline \multirow[t]{2}{*}{ Co-op } & $-.0423 * * *$ & $-.0422 * * *$ & $-.0419 * * *$ & $-.0417 * * *$ & $-.0419 * * *$ & $-.0418 * * *$ \\
\hline & $(.0093)$ & $(.0093)$ & $(.0093)$ & $(.0093)$ & $(.0093)$ & $(.0093)$ \\
\hline \multirow[t]{2}{*}{ Twin-house } & $-.0695 * * *$ & $-.0693 * * *$ & $-.0692 * * *$ & $-.0690 * * *$ & $-.0693 * * *$ & $-.0693 * * *$ \\
\hline & $(.0058)$ & $(.0058)$ & $(.0058)$ & $(.0058)$ & $(.0058)$ & $(.0058)$ \\
\hline \multirow[t]{2}{*}{ Row-house } & $-.1131 * * *$ & $-.1131 * * *$ & $-.1129 * * *$ & $-.1128 * * *$ & $-.1126^{* * *}$ & $-.1128 * * *$ \\
\hline & $(.0064)$ & $(.0064)$ & $(.0064)$ & (.0064) & $(.0064)$ & $(.0064)$ \\
\hline \multirow[t]{2}{*}{ Apartment } & .0031 & .0032 & .0032 & .0032 & .0029 & .0034 \\
\hline & $(.0073)$ & $(.0073)$ & $(.0073)$ & $(.0073)$ & $(.0073)$ & $(.0073)$ \\
\hline \multirow[t]{2}{*}{ Constant } & $11.53^{* * * *}$ & $11.52 * * *$ & $11.52 * * *$ & $11.52 * * *$ & $11.51 * * *$ & $11.52 * * *$ \\
\hline & $(.0397)$ & $(.0395)$ & $(.0396)$ & $(.0396)$ & $(.0395)$ & $(.0395)$ \\
\hline Zip-codes & Yes & Yes & Yes & Yes & Yes & Yes \\
\hline Years & Yes & Yes & Yes & Yes & Yes & Yes \\
\hline Months & Yes & Yes & Yes & Yes & Yes & Yes \\
\hline $\mathrm{R}-\mathrm{Sq}$ & .6901 & .6901 & .6902 & .6905 & 6909 & .6909 \\
\hline
\end{tabular}

a. Dependent variable: Ln (Price+0.86*MUT). Robust (Huber-White) standard errors in parentheses. Stars indicate statistical significance, with * denoting 5\% level, ** $1 \%$ level and $* * * 0.1 \%$ level

Regression A, while Rob-2 shows results from estimation Regression A using $\widehat{\zeta}=0.70$. Comparing Rob-1 and Rob-2 with Regression-A it is evident that the estimated treatment parameter is robust towards even very large variations in the mutual debt parameter. Moreover, except for the parameter affiliated with the Co-opvariable the other coefficients in Rob-1 and Rob-2, including the treatment coefficients, are very similar to the corresponding coefficients in Regression A. The fit of Regression A is also slightly better than that for Rob-1, and very similar to that of Rob- 2 . Hence, we conclude that using $\widehat{\zeta}=0.86$ as prior information in the estimation seems to be unproblematic.

Rob-3 in Table 7 shows results from a placebo analysis, where the treatment effect is assumed to materialize as early as in 2004 , i.e. one year before the decision to build the new highway was made. The estimated treatment parameter is close to zero and statistically insignificant, indicating that housing prices in the treatment region did not divert from those in the control region as early as in the year prior to the final decision to build the new highway. 


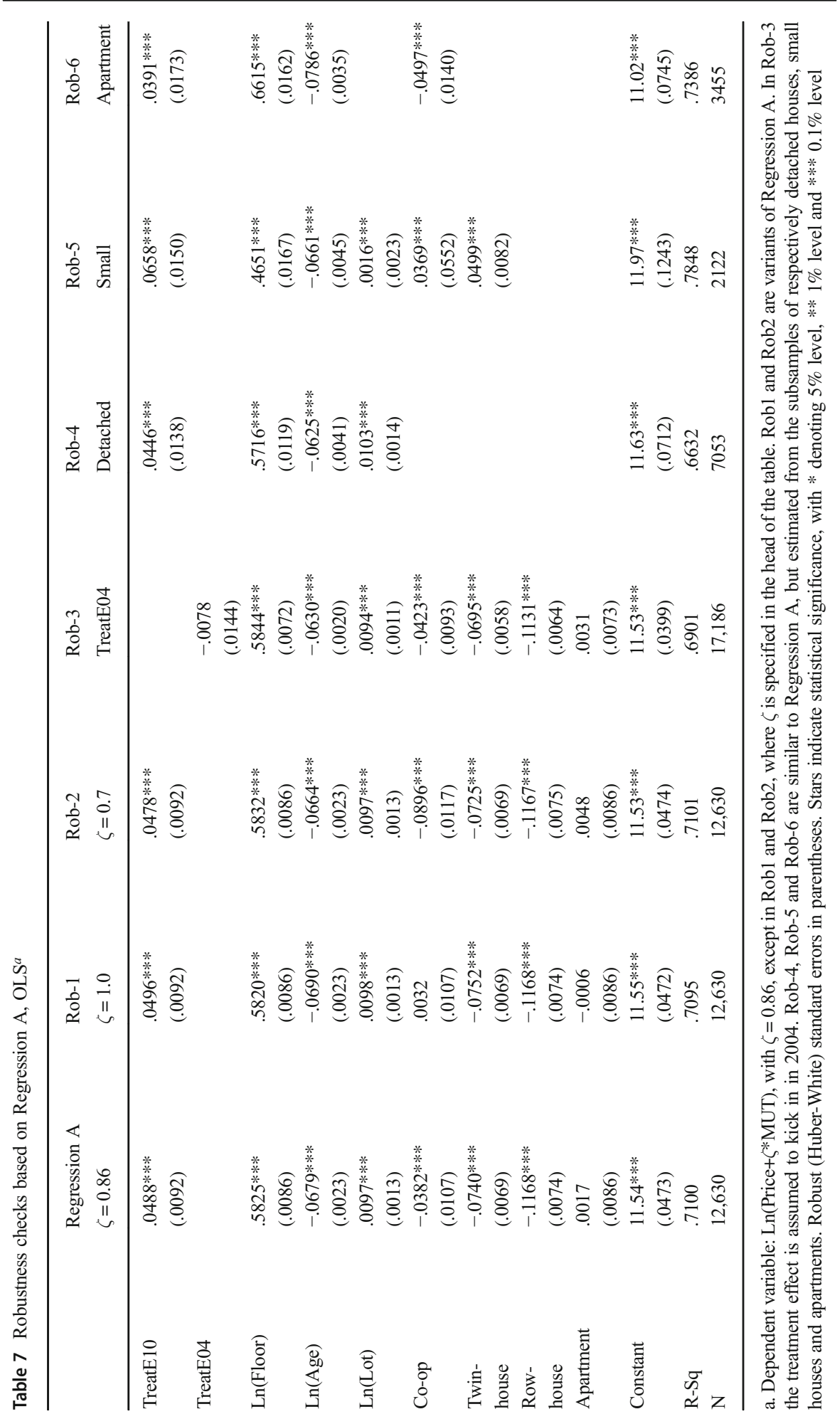


In regressions Rob-4, Rob-5 and Rob-6 in Table 7 we have re-estimated Regression A separately for detached houses, apartments, and small houses (row-houses and twinhouses taken together). The estimated treatment parameters for the three types of dwellings are all positive and statistically significantly different from zero. The dwelling-type specific parameter estimates are not statistically significantly different from the treatment parameter in Regression A, but the differences are sufficiently large to warrant a closer examination.

In Table 8 we present results from estimating Regression A separately for three types of dwellings, with alternative assumptions on when the treatment effect kicks in. Hence, the estimated relationships are of the same type as those in Table 6, except that they are dwelling-type specific in Table 8 . We observe from Table 8 that the estimated treatment coefficients for each of the three dwelling types are roughly of the same magnitude for the years 2009 and 2010, while the estimates for earlier years are smaller. Hence, for each of the three dwelling types, it seems that the full treatment effect materializes towards the end of the construction period. Since the estimated coefficients for detached houses, small houses and apartments are far from being statistically significantly different from each other, this provides evidence that the full treatment effect is similar for all types of dwellings.

Consider now the results obtained by assuming that the treatment effect kicks in in alternative years before 2009. The regressions in column 2008 in Table 8 are based on the presumption that the treatment effect kicks in in 2008, and show that the magnitude of the estimated treatment coefficient is much larger for small houses and apartments than for detached houses. Moreover, for small houses and apartments the estimated treatment effects in column 2008 are almost as large as those in columns 2009 and 2010. Hence, from the results in Table 8 it seems warranted to conclude that the treatment effect for apartments and small houses kicks in with considerable magnitude already in the middle of the construction period. For detached houses by contrast, the estimates in Table 8 indicate that the treatment effect in the middle of the treatment period is much weaker. Finally, from the results in Tables 8 and 6 there are indications of a small treatment effect also in 2007 , the year when construction of the new road started up. Hence, we conclude that the treatment effect seems to kick in somewhat earlier for apartments and small houses, and that the early effects also seem to be stronger for such dwellings than for detached houses.

The observations just made deserve some elaboration. An important reason why the treatment effect does not kick in before the year construction of the new road started may be that people do not react before they with their own eyes see that construction of the new road has started. Next, there may be several reasons why the treatment effect in the middle of the construction period according to our results seems to be stronger for small houses and apartments: First, most apartments and small houses are more standardized than detached houses, i.e. comparable apartments and small houses are easily found. Market actors may then easily find comparable units recently sold. Adjustment of asking price to a realistic level may then work smoother than for detached houses, where it may be hard to find similar houses recently sold within the same local environment. In addition, sellers of detached houses in the markets we consider often may have to wait quite long before the "right" bidder turns up and hands in his or her bid. Consequently, sellers of detached houses may often be uncertain why he or she does not see a "sufficiently high" bid: Is it because the asking price is too high 


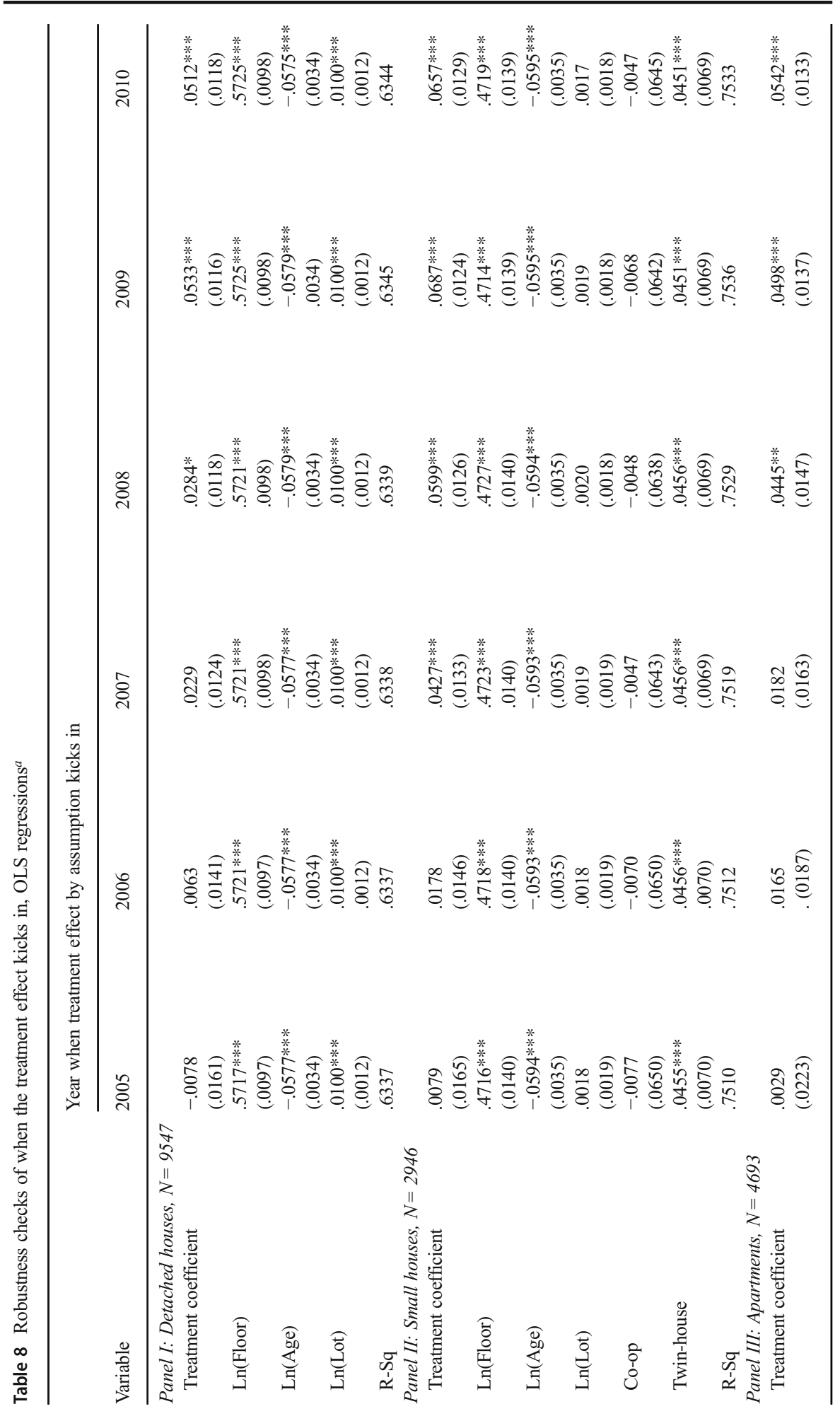




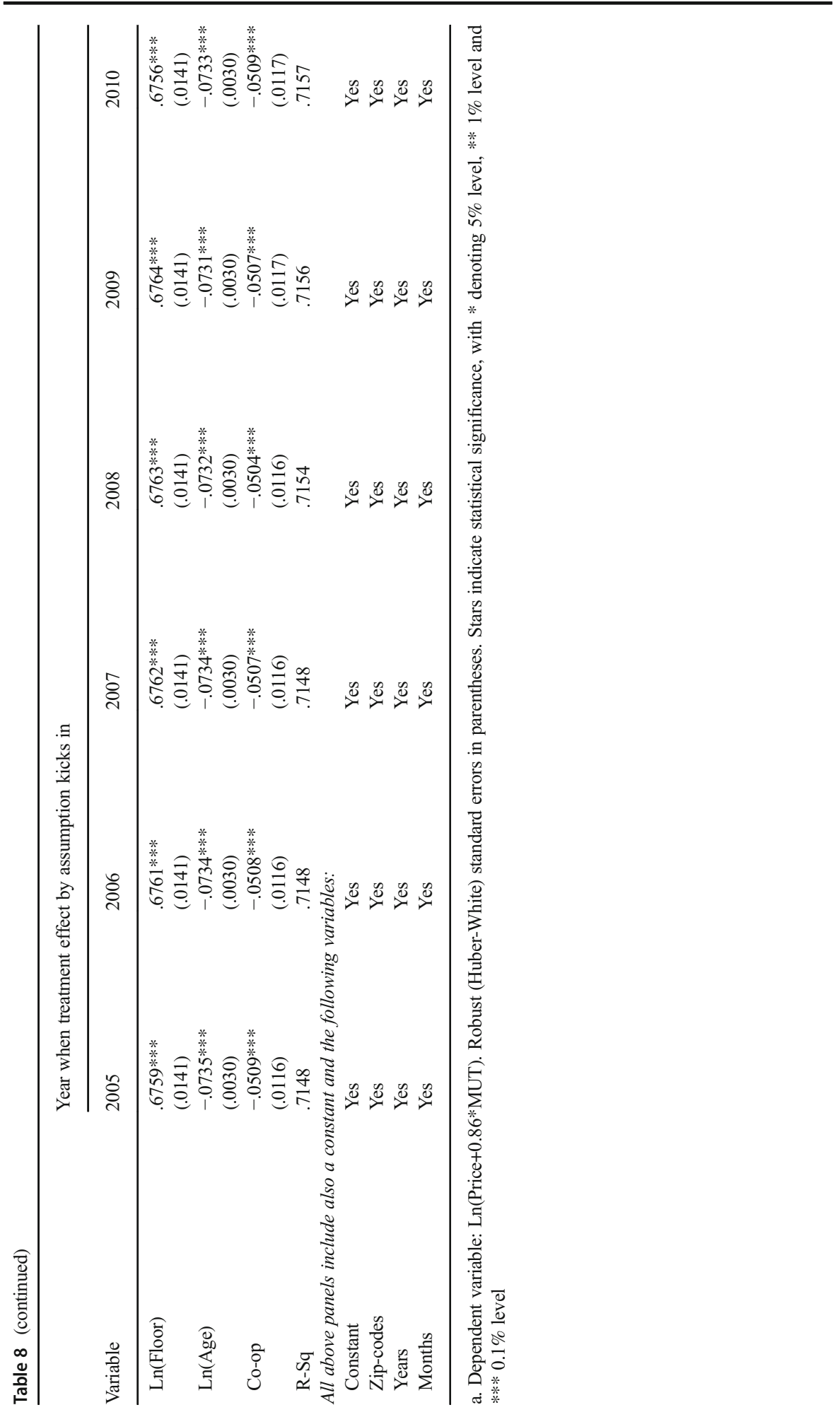


or because the "right" bidder has not yet turned up? This may slow down the sales process, price adjustment, and thereby also discounting of the new highway into housing prices.

Before concluding the robustness checks, we add a couple more technical points. First, residual plots for our regressions revealed some observations with large residuals. Closer examination of these showed, however, that outliers did not impact estimated parameters very much. Hence, we have not excluded any observations from the data set.

A final caveat relates to the zip-codes, which we have used to control for the location of houses. As argued in the econometrics section, in this study we prefer to use zipcodes rather than distance variables. Each of our zip-codes contains on average about 3000 residents, which roughly corresponds to somewhat more than 1000 dwellings. This is much less than the 14,300 residents in the zip-codes used by Hill and Scholz (2017), who argue that the zip-codes they used to control for the impact of location on housing prices worked almost as well as using continuous geospatial data. It is important that zip-codes are narrowly defined, though, and do not cover areas on both sides of a fiord, etc. Our zip-codes meet very well these requirements.

\section{Concluding Remarks}

Within a stylized theoretical model we showed that the building of a new highway parallel to an existing road in a region with one large Core town and several smaller treatment towns, all located like pearls on a string, leads to higher housing prices in the smaller towns and lower prices in the Core town. The empirical analysis confirms this predicted change in relative housing prices: housing prices in town A, $30 \mathrm{~km}$ (19 miles) from the Core town, increased by about 13\%, while prices in town $\mathrm{B}, 50 \mathrm{~km}$ (31 miles) from the Core town, increased by about $9 \%$. In town $\mathrm{C}, 70 \mathrm{~km}$ (43 miles) from the Core town, however, the new highway did not increase housing prices, despite that the reduction in travelling time from town $\mathrm{C}$ to the Core town was equally large as from town B. Our results at this point are in accordance with Osland et al. (2007), who also found that housing prices were least affected in the areas with the longest commutes. One possible explanation why we did not find any impact of the new road on housing prices in town $\mathrm{C}$ may be that the distance from town $\mathrm{C}$ to the Core town is beyond an acceptable daily commuting distance. An additional reason may be that town $\mathrm{C}$ has a better balance between population and workplaces than towns $\mathrm{A}$ and $\mathrm{C}$ have, and that commuting between town $\mathrm{C}$ and the Core town also for this reason always has been modest.

Economists typically argue that investments in infrastructure will be capitalized into housing prices at the time when the investment decision is made. Our results indicate that housing prices in the treatment towns may have started to increase slightly soon after construction of the new road started up, but the full treatment effect materialized first when the new highway was opened. This is in line with what Chernobai et al. (2011) found from studying prices of houses located adjacent to a new section of an interstate road in USA. In our view there may be at least two explanations for why a new infrastructure project is not discounted into housing prices at the time of decision: First, information about the decision to build the new highway may not be perceived by 
the public. Second, even if the decision is known to the public, many may suspect that it will not be implemented, or that construction of the new highway may be seriously delayed. Only when construction work has started, will such doubts be swept away. After construction has started up market reactions may, however, still be sluggish. Hence, the full impact on housing prices does not materialize until the new highway is opened for traffic.

Our results showed that prices of apartments and small houses in the middle of the construction period increased more than prices of detached houses. An interpretation of this is that the market for small houses and apartments seems to work more efficiently than for detached houses. A possible explanation may be that for detached houses there is a higher degree of uncertainty with respect to what is the "right" asking price, and that this slows down the discounting of the new highway into housing prices.

We find that the new highway leads to an increase in housing prices by about $13 \%$ in town $\mathrm{A}$, and about $9 \%$ in town $\mathrm{B}$. These price changes imply that total housing capital in these two towns increased by approximately 2,760 million NOK (308 million US $\$)^{7}$ due to the new highway. ${ }^{8}$ By comparison, the total construction costs for the road amounted to 3300 million NOK (369 million US \$). ${ }^{9}$ It is indeed amazing that the increase in housing capital in the two treatment towns benefiting the most from the new highway amounts to almost $84 \%$ of the total costs, despite the fact that commuting between town $\mathrm{B}$ and the Core town has been modest in the past. Accounting for the time saved also by long-distance traffic using the new highway, and other positive impacts, one may therefore argue that the project of building this new highway most likely have benefits far exceeding costs.

We have used a Norwegian data set to examine the impact of improved road standards on housing prices in a region with towns located like pearls on a string along both a new highway and an old road. What about the external validity of the results? In our view, the results should be of relevance to similar road projects, i.e. for the impact on housing prices of construction of a new highway parallel to an existing road, thereby improving the connection from a smaller town (or towns) to a major town and reducing commuting time. Similar projects in European or North American countries, where commuting by car plays an important role, will probably have comparable, but certainly not identical, implications.

Acknowledgements We are very grateful for the constructive comments from an anonymous referee and from Liv Osland. We also benefited from comments received at the international conference of the American Real Estate and Urban Economics Association in Milan 2019. All remaining errors are our own.

\footnotetext{
${ }^{7}$ According to the web-page of the Norwegian Central Bank, on September 18th 2019, 1 US $\$=8,9482$ NOK, 1 Euro $=9.8905$ NOK.

${ }^{8}$ In town A (Lillesand), there were 3999 dwellings at the end of 2009, and in town B (Grimstad) 8388 dwellings. The increase in total housing capital is calculated as $2,229,125 \times 0.132 \times 3999+2,031,797 \times$ $0.093 \times 8388$.

${ }^{9}$ Construction costs according to the contract signed between Statens Vegvesen and the contractor. Since the estimate of the impact of the new road on housing prices is based on average prices over the period 20032013, construction costs and increase in housing capital are measured in prices referring to approximately the same point in time.
} 
Funding Information Open Access funding provided by University of Agder.

Open Access This article is licensed under a Creative Commons Attribution 4.0 International License, which permits use, sharing, adaptation, distribution and reproduction in any medium or format, as long as you give appropriate credit to the original author(s) and the source, provide a link to the Creative Commons licence, and indicate if changes were made. The images or other third party material in this article are included in the article's Creative Commons licence, unless indicated otherwise in a credit line to the material. If material is not included in the article's Creative Commons licence and your intended use is not permitted by statutory regulation or exceeds the permitted use, you will need to obtain permission directly from the copyright holder. To view a copy of this licence, visit http://creativecommons.org/licenses/by/4.0/.

\section{References}

Alonso, W. (1964). Location and land use: Towards a general theory of land rent. Cambridge: Harvard University Press.

Chernobai, E., Reibel, M., \& Carney, M. (2011). Nonlinear spatial and temporal effects of highway construction on house prices. Journal of Real Estate Finance and Economics, 42(3), 348-370.

Cropper, M. L., Deck, L. B., \& McConnell, K. E. (1988). On the choice of functional form for hedonic Price functions. Review of Economics and Statistics, 70(4), 668-675.

Gjestland, A., McArthur, D. P., Osland, L., \& Thorsen, I. (2014). The suitability of hedonic models for cost-benefit analysis: Evidence from commuting flows. Transportation Research: Part A: Policy and Practice, 61, 136-151.

Hill, R. J., \& Scholz, M. (2017). Can geospatial data improve house Price indexes? A hedonic imputation approach with splines. Review of Income and Wealth, 64(4), 737-756.

Imbens, G. W., \& Wooldridge, J. M. (2009). Recent developments in the econometrics of program evaluation. Journal of Economic Literature, 47(1), 5-86.

Jacoby, H. C. (2000). Access to markets and the benefits of rural roads. Economic Journal, 110(465), 713-737.

Kilpatrick, J. A., Throupe, R. L., Carruthers, J. I., \& Krause, A. (2007). The impact of transit corridors on residential property values. Journal of Real Estate Research, 29(3), 303-320.

Mikelbank, B. A. (2004). Spatial analysis of the relationship between housing values and Investments in Transportation Infrastructure. Annals of Regional Science, 38(4), 705-726.

Mills, E. S. (1972). Urban economics. Glenview: Scott, Foresman and Company.

Ministry of Transport (2000a): St.meld. $n r$. 46(1999-2000) National transportplan 2002-2011. Oslo: Ministry of Transport.

Ministry of Transport (2000b): St.prp. $n r$.30(2000-2001) Om delvis bompengefinansiert utbygging av deler av E18 i Aust-Agder. Oslo: Ministry of Transport.

Mohring, H. (1961). Land values and the measurement of highway benefits. Journal of Political Economy, 69(June), 236-249.

Muth, R. F. (1969). Cities and housing: The spatial pattern of urban residential land use. Chicago: University of Chicago Press.

Osland, L. A., Thorsen, I., \& Gitlesen, J. P. (2007). Housing Price gradients in a region with one dominating center. Journal of Real Estate Research, 29(3), 321-346.

Robertsen, K., \& Theisen, T. (2011). The impact of financial arrangements and institutional form on housing prices. Journal of Real Estate Finance and Economics, 42(3), 371-392.

Sandow, E., \& Westin, K. (2010). Preferences for commuting in sparsely populated areas: The case of Sweden. The Journal of Transport and Land Use, 2(3), 87-107.

Shen, G. (1999). Estimating nodal attractions with exogenous spatial interaction and impedance data using the gravity model. Papers in Regional Science, 78(2), 213-220.

Solow, R. M. (1972). Congestion, density and the use of land transportation. Swedish Journal of Economics, 74(1), 161-173.

Voith, R. (1993). Changing capitalization of CBD-oriented transportation systems: Evidence from Philadelphia, 1970-1988. Journal of Urban Economics, 33(3), 361-376.

Waddell, P., Berry, B. J. L., \& Hoch, I. (1993). Residential property values in a multinodal urban area: New evidence on the implicit Price of location. Journal of Real Estate Finance and Economics, 7(2), 117-141.

Publisher's Note Springer Nature remains neutral with regard to jurisdictional claims in published maps and institutional affiliations. 